\title{
Advance Directives in English and French Law: Different Concepts, Different Values, Different Societies
}

\author{
Ruth Judith Horn
}

\begin{abstract}
In Western societies advance directives are widely recognised as important means to extend patient self-determination under circumstances of incapacity. Following other countries, England and France have adopted legislation aiming to clarify the legal status of advance directives. In this paper, I will explore similarities and differences in both sets of legislation, the arguments employed in the respective debates and the socio-political structures on which these differences are based. The comparison highlights how different legislations express different concepts emphasising different values accorded to the duty to respect autonomy and to protect life, and how these differences are informed by different socio-political contexts. Furthermore each country associates different ethical concerns with ADs which raise doubts about whether these directives are a theoretical idea which is hardly applicable in practice.
\end{abstract}

Keywords Advance directives · Autonomy $\cdot$ Welfare $\cdot$ Solidarity $\cdot$ Responsibility England · France

\section{Introduction}

While progress in medicine has given rise to more therapeutic opportunities, it has led also to new questions regarding the limits of physicians' duty to provide the best medical care and their duty to respect patients' wishes. Comparing different countries, these duties enter more or less strongly into conflict depending on the way autonomy is defined in a certain society. In this paper, I highlight these differences by comparing England and France, both characterised by different philosophical and

R. J. Horn (ه)

Centre for Ethics in Medicine, University of Bristol, 39 Whatley Road, Bristol BS8 2PS, UK

e-mail: ruth.horn@bristol.ac.uk 
socio-political backgrounds. More explicitly, I discuss these differences as they relate to advance directives (ADs).

As we will see, the situation regarding ADs in terms of their legal status and acceptance differs in France and England. Even though both countries have witnessed legal developments in relation to ADs and respect for patient autonomy appears to be, as is most Western countries [38, p. 26], an important value, one can observe differences that refer to varying normative, legal and social models. In the first section, I will explore the different legislation and their development. Then, I will compare the different arguments each country employs regarding the authority of ADs. As we will see, these arguments point to the weight accorded to either autonomy or to physicians' duty to protect life. In the final section, I will highlight how these differences reflect either an individualistic, liberal society or instead a community-oriented society. Furthermore, each country associates different ethical concerns with ADs which raise doubts about whether these directives are a theoretical idea which is hardly applicable in practice.

\section{Methodology}

In order to explore the differences between the English and French approaches to advance directives I undertook literature-based research using e.g. search engines such as PubMed and the French Inter University Library Catalogue BIUM (http://www.bium.univ-paris5.fr/). I searched for articles regarding "advance directives", "living wills", "treatment withdrawal", etc. I read relevant legal texts (laws, rulings), parliamentary reports regarding advance directives, professional guidelines and academic (philosophical, legal, medical) literature on the subject in both countries. I could thus identify and compare recurrent themes and specific terms employed in each debate regarding the legal status of ADs. This approach enabled me to explore differences between the countries and the moral preoccupations that each society associates with advance directives.

\section{The English Law: The Priority of Patients' Preferences Over the Duty to Safe Life}

\section{Legal Developments in Common Law}

Before examining the current legislation governing ADs, we should note that anticipated patients' wishes to refuse treatment were already binding under English common law. For many years, in English law, respect for (patient) autonomy has been a dominant principle, which is often placed over the doctor's duty to provide best medical care in order to save life. For the first time in 1985, Lord Templeman acknowledged that after a physician had informed the patient of the inherent and material risk of the proposed treatment the patient is entitled to "reject [the] advice for reasons which are rational, or irrational, or for no reason" [49, pp. 904-905]. 
Although Sidaway ${ }^{1}$ on the occasion of which this statement was made did not explicitly concern a treatment refusal, these passages from Lord Templeman were quoted later in other cases where they served to underline patients' right to autonomy - in the sense of honouring treatment refusals [50, p. 337; 20].

Further cases confirmed that a patient has the right to refuse treatment as far as, at the time the statement is made, the patient is informed, that they are not under undue influence and that the statement concerns a specific situation or treatment. In $\operatorname{Re} C$ [42] for example, the judges found that even if the patient's reasoning was impaired in some ways by schizophrenia his advance refusal of a life-saving leg amputation was valid because $\mathrm{C}$ did sufficiently comprehend the information, believe in the validity of the information and had the ability to weigh up the benefits of the treatment he refuses. ${ }^{2}$ Further opportunities to confirm the principle of respect were the cases of $\operatorname{Re} A K$ [40] and $\operatorname{Re} B$ [41]. Evidently, then, in English law a person's right to make their own decisions can be placed above the doctor's duty to save life. Yet, in spite of this dominant model, the court defends also the need to protect persons whose competence and awareness of the situation is impaired at the moment that a decision is needed.

In $R e T$ for example, the court confirmed that the alleged directive did not stand because the patient first consented to a blood transfusion and refused it later, only after having spoken with her mother who was a Jehovah's Witness. Nevertheless, Butler-Sloss reminded the importance to accord "very high priority" to "free individual choice" where possible [43, pp. 116-117]. Another case where the court held that there were "reasonable grounds for believing" that the advance refusal of blood transfusion was not valid anymore was HEv A Hospital NHS Trust [23]. The patient was brought up as a Muslim, became after the parent's divorce as her mother a Jehovah's Witness and had signed a blood refusal card. Yet, a few months prior to the accident she became engaged with a Muslim and did not attend any Jehova's Witness meetings anymore. The advance directive would have been binding if there would have been no doubt that the patient changed in faith and if she would have mentioned the $\mathrm{AD}$ in the course of a hospital appointment and knowing of her illness. This case had a considerable impact on the way the conditions under which ADs are applicable were formulated in the Mental Capacity Act 2005 (MCA).

\section{ADs Under Statutory Law}

Since the MCA came into force in October 2007, ADs are legally binding under English statute law. Under the Act, a person who is over 18 and has capacity (section 2.1$)^{3}$ can anticipate the refusal of a specific treatment for the moment they

\footnotetext{
${ }^{1}$ In this case a patient claimed for damages because she developed paraplegia as a result of a spinal operation without having been told that this can occur in very rare (1\%) cases [48].

2 These criteria became the standard test for competence in England until the MCA which retains the functional approach, according to which the crucial element is the individual's ability to understand the nature, purpose and benefits of a treatment (See test of capacity Mental Capacity Act Code of Practice, chapter 4).

3 The Act specifies that "a person lacks capacity in relation to a matter if at the material time he is unable to make a decision for himself in relation to the matter because of an impairment of, or a disturbance in the functioning of, the mind or brain".
} 
will lack capacity by a verbal statement. In case the anticipated wish concerns a withdrawal the AD must be written (section 24.4). Where the refusal is to apply to life-sustaining treatment and may thus result in the patient dying this must be explicitly stated in the written, signed and witnessed AD-there are no specific requirements regarding the witness (sections 25.5, 25.6). The advance directive must be clear, refer to the concrete situation and be consistent with the patient's actions (sections 25.2 and 25.4). In introducing the specific concept of an "advance decision to refuse treatment" the Act makes clear that such a directive justifies neither an active act causing the death of a patient nor demands for treatment (sections 24-26). There is a clear distinction drawn in English law between the patient's right to refuse and the right to request a treatment. In Mr Leslie Burke v $G M C$ [36] it was held that a patient has no right to determine what treatment he should receive, including artificial food and fluids.

The MCA also provides a basis for lasting power of attorneys (LPAs) appointed and registered by the patient whilst she is competent in order to make decisions in her "best interests" if she loses capacity (section 9). As this paper focuses on ADs I will give no further details regarding LPAs.

Indeed, the Act is underpinned by the best interests standard which requires that the person-physician or LPA—who makes decisions on behalf of an incompetent person must: permit the latter to participate, so far as possible and reasonable in any decision regarding them; not be motivated by a "desire to bring about [the] death" of the patient; consider the person's past and present wishes, feelings, beliefs, values and any other factor the person would consider if they were able to do so; and take into account the opinion of any other person that could contribute to determining what would be in the person's best interests (section 4.4-4.7).

Despite the value accorded to individual preferences and wishes when determining the best interests of an incompetent person, a patient's best interests need not necessarily be in accord with the patients' presumed wishes but might be determined by medical knowledge as to what is the best treatment in a given situation. Hope et al. [24, p. 734] highlight indeed the fact that the Act does not explicitly define the best interests "in terms of the advance decision the person may have made". The authors suggest that this might point to the difficulty to actually validate and apply an advance directive. One of the problems is that we will never be able to know what decision a currently incompetent person would make in a concrete situation if she happened to be competent, and whether she would stick to the wishes she expressed in previous situations.

Cases such as the aforementioned HEv A Hospital NHS Trust [23] or recently $W$ $v M$ and $S$ and $A$ NHS Primary Care Trust [52] have shown the difficulty when there is a doubt about the authenticity and interpretation of previous wishes. In $W v M$ and $S$ and A NHS Primary Care Trust, the family of a patient in a minimally conscious state insisted that the patient $M$ had made previous statements that she would not want to continue life in her current condition. In accordance with the MCA, the Court of Protection did not recognise these statements as legally binding directives because they concerned neither a concrete refusal of CANH nor were formally written down. As there was no valid and applicable advance decision to refuse treatment (in the terms of the Act), the case turned on M's best interests. It was held 
that discontinuing clinically assisted nutrition and hydration (CANH) was not in the patient's best interests because $\mathrm{M}$ still had some awareness of her situation and responded to some negative and positive stimuli (pain, dis-/comfort, music).

Cases like this, as well the definition of criteria under which an AD is legally binding under the MCA, point to the difficulty in determining the right balance between the two imperatives of respect for autonomy and welfare/protection of life. Yet, as Dunn and Foster [14] emphasises, these two principles are not necessarily "enemies" and decisions such as those in the aforementioned cases, which may at first glance seem in favour of welfare, might at second glance favour the protection of the patient's current views and experiences. Indeed it appears that there is a tendency in English law to accord priority to autonomy and freedom of choice even in cases where an advance directive is not valid which cannot be denied [19]. In other words, the fact that $\mathrm{M}$ sometimes exhibited pleasure might seem to have led to the conclusion that it was her current wish that her life continues.

Before depicting the arguments employed in the English debate leading to the enshrining of ADs in statutory law, I will move in the next section to consider how the issues are framed and dealt with in France.

\section{The French Law: The Priority of Medical Practice Over Patients' Preferences}

In French law, ADs were mentioned for the first time in a law about patients' rights and end-of-life decision-making, "loi relative aux droits des malades et à la fin de vie”, in 2005 [29]. The French term "directives anticipées" as employed in this law, is a direct translation of the English expression "advance directives" and replaced only gradually the term "testament de vie" (living will) principally associated with the requests formulated by the euthanasia-lobby. ${ }^{4}$ As has also been the case in England, since the 1980s such lobbyists have promoted the idea of living wills, in the sense of documents enabling incompetent patients, not only to refuse excessive medical treatment at the end of life, but also to request a lethal injection in case of unbearable suffering [25]. The reluctance of the government as well as of doctors to introduce documents allowing anticipating treatment preferences points at least partly to this precursor. ${ }^{5}$

\footnotetext{
4 Two Information Reports, (Assemblée Nationale) one of 2004 which preceded the law of 2005, and one of 2008 which evaluates the law of 2005, are the most complex documents concentrating public and professional opinions, policies and studies regarding end-of-life issues in France today. 80 interviews were conducted in 2004 and 81 in 2008 with representatives of various public and professional milieus (politicians, physicians, natural scientists, human scientists, social scientists, pro-life/pro-euthanasia lobbyists, etc.). Counting how often the expression was employed during the interviews made for the Information Reports of 2004 and 2008, one discovers that the expression "advance directives" appears 99 times in 2008, but only three times in the report of 2004. On the contrary, the expression "living will" is used 180 times during the auditions for the report of 2004, but only 3 times in 2008.

5 This conclusion abounds throughout the press and is also emphasised in a to date unpublished study on the view of the elderly on advance directives carried out by the Centre d'Ethique Clinique in Paris, paper presented at Etre vieux est-ce préparer sa mort? Les directives anticipées vues par les personnes âgées, MGEN, Paris, 11 October 2011.
} 
The main purpose of the law introducing ADs on a legal level is to specify both the conditions under which a physician can lawfully discontinue treatment at the end of life (L. 1111-4 CSP, Public Health Code) and the right of a patient to refuse life-sustaining treatment (L. 1111-10 CSP). ${ }^{6}$ Yet, the doctor is not required to accept such a request, but is advised to "do all that is possible in order to convince the [competent] patient" to continue the treatment when the refusal endangers the patient's life. It is not specified what is meant by doing "all that is possible". If the patient is incompetent, the doctor has now the explicit right to withhold or withdraw treatment if she judges that this aims only to extend life artificially. The doctor has to discuss such a decision with colleagues and to consult a representative (personne de confiance), a relative or, where existent, the $\mathrm{AD}$ of the concerned person. The right to appoint a representative that should be consulted and informed of therapeutic decisions has been introduced by a law on patients' rights and the quality of the health system, "loi relative aux droits des maladies et à la qualité du système de santé”, in 2002 [28]. Unlike LPAs in English law, a representative cannot substitute under certain conditions an incompetent person's decision. In the same way, it is held that an AD in French law "can be taken into account" by the physician, supposing it was signed not more than three years ago (L. 1111-11 CSP). There is, however, no obligation for the physician to respect an $\mathrm{AD}$ and, ultimately, it is for the doctor to decide whether or not to discontinue a treatment (L. 1111-5 $\mathrm{CSP}$ ). It is not required that an $\mathrm{AD}$ signed by the patient is witnessed by another person. ADs in French law seem to be simple "indications" of wishes and can thus not prove the patient's will [18, p. 203]. These limitations on the validity of ADs, recall the objections that a patient may change their mind over the years and medical techniques and treatment opportunities may develop and thus invalidate an anticipated wish. There is no explication why the validity has been limited to 3 years.

The fact that ADs have no obligatory value indicates the relatively weak position of patient self-determination in regard to treatment refusal in French law; it points also to the particular context which generated the law of 2005. In contrast to the English situation, the introduction of ADs into French legislation was not the result of a jurisprudence favouring over many years the acceptance of incompetent patients' advance refusals of treatments. The new law emerged in answer to the case of Vincent Humbert, a patient who claimed publicly the right to receive euthanasia after he was tetraplegic as a result of a car accident [25]. When his request was refused, his mother administered to him a high dosage of barbiturates which plunged her son into a coma, until the responsible doctor employed a lethal dosage of potassium chloride in order to end both the patient's suffering and his life. In answer to this case, the law, until that point amongst physicians often seen as a source of uncertainty with regard to modalities for treatment withdrawal and use of analgesics [32], tended then to fix a clear framework for legal or illegal medical practices at the end-of-life, rather than a framework for respecting patients'

\footnotetext{
6 The new law of 2005 specifies that a terminally ill patient has the right to refuse "every" treatment, including artificial alimentation and hydration. Prior to this law, the law $n^{\circ} 2002-303$ introduced in 2002 the right to refuse "a" treatment without specifying that this concerns life-sustaining treatments at the end of life.
} 
autonomy [4, pp. 404-405]. Nevertheless, the authors of the law took into account discussions about patients' self-determination in other Western countries namely England, Germany, the Netherlands and Belgium [4, pp. 257-260]. Thus, ADs were considered without being assumed as binding upon physicians. Although there is a development in France, namely since the before mentioned law of 2002 [28], towards a more patient-centred approach, it appears that well entrenched traditions do not change immediately. Thus, an important weight is still accorded to the physician's opinion rather than to the patient's viewpoint. In the next section we will further see that the physician's responsibility for their patients' physical wellbeing and their ultimate authority to make decisions on the patient's behalf is apparent not only in the law but also in the French debate about the legal status of ADs. On the other hand we will also see how strongly patient autonomy is defended in England and how the English discussion tends to focus upon problems surrounding the authenticity of the exercise of autonomy attempted in an AD.

\section{Beyond and Behind the Law: Debating the Advantages and Disadvantages of ADs in England and France}

Controversies regarding advantages and disadvantages of the legal recognition of ADs cover in both countries a variety of different issues. The key themes here seem to be: the problem of the authenticity of autonomy; the authority of ADs; the risk that physicians lose their sense of responsibility to take care of the patient; and, thus the risk of abandoning the patient. Whereas some of these issues are evoked in both England and France, they are not discussed in the same way in each country and some themes seem to emerge in only one country.

Scepticism towards ADs is not specific to a certain country but has been raised in various countries. After having considered that ADs "desirably serve a strong version of patients' autonomy" some authors such as Fagerlin and Schneider in the USA "contend, nevertheless, that living wills do not and cannot achieve that goal" $[17$, p. 30]. Reasons given for this critique are that only few people actually execute ADs, know what they really want and can articulate their wishes, and that people fear misinterpretations of their ADs not being taken into consideration. Other studies evidence that individuals may express different treatment preferences when they are healthy than when they are ill [12]. It appears that most discussions in the broader international context, whether they concern problems in according "absolute" or "relative" 8 authority to precedent wishes, raise concerns about the best protection of, and guarantees to, autonomous decision-making.

This argument is the subject of debate in both England and France. Since the first important debates on decision-making for incompetent persons took place in

\footnotetext{
7 Dworkin defends the idea that past preferences should always be respected because of the individual's "right to a life structured by his own values"; values that are to be placed over present "experiential" interests of the incapacitated person such as quality of life, contentment or lack of pain [16, pp. 201-202; 224].

${ }^{8}$ Referring to Parfit [39, p. 216], Dresser considers that personal identify, and thus values judgments, develop continually depending on various external and psychological factors [13, p. 379].
} 
England in the wake of Airedale NHS Trust $v$ Bland, one of the main objections to ADs is the risk that not all statements may be "truly voluntary". 9 This objection concerns the risk of misinterpretations or changes of mind between the time the person has written the directive and the time of its application. In the French Information Report 2004 that preceded the law of 2005, it was found that in order to protect freedom of choice "respect for the body", and thus the preservation of life, should be clearly placed above respect for an anticipated wish if there is any doubt about whether the patient has changed mind [2, p. 45]. This argument of 'false' autonomy was arguably a major reason why ADs in England were not included in statute law until the MCA which came into force in 2007 and remains an important obstacle to their attaining obligatory value in France.

Yet, unlike the French debate, the English debate introduced a new element, communication, which invites consideration of the authenticity of the purportedly autonomous statement, and thus the authority of ADs. For the first time in [7], the BMA emphasised advance statements as means of initiating difficult communication about end-of-life issues and improving understanding of patients' wishes, not only regarding a specific situation, but also their general wishes and preferences. Further, in the GMC's guidance on consent of [21] and on end-of-life care of 2010, it is stated that the physician should encourage the patient to think about future treatment and discuss with them their wishes, preferences or fears in relation to these issues. Indeed, improving the doctor-patient-dialogue and better discerning the patient's wish could be an important means in interpreting and thus assessing the validity and applicability of an $\mathrm{AD}$, as requested in the MCA.

In France, although the protection of freedom of choice is an important argument, it appears to be not the only and apparently not the principal one. Indeed, there is great concern that physicians will be reduced to executors of patients' wishes, without their own power of judgement, if they were to be obliged to respect ADs [2, p. 17]. Thus, patients could lose confidence in their physician's professional competence [44, p. 400] and physicians could abandon their patients and discharge themselves of their duty to care for them [4, p. 25]. The idea that the doctor takes an active role in order to understand the patient's wishes does not appear in the French debate. It is, on the contrary, argued that ADs may weaken both the family's and physician's sense of responsibility for the patient's physical welfare and solidarity with the vulnerable person [3, p. 214]. Following this conception of responsibility, the duty to respect patient autonomy seems to be overridden by the principle of beneficence [5]. There is no formal requirement that physicians should "listen to and consider the views of the patient", as recommended by the GMC in England [22]. Although the French law stipulates that the doctor who makes decisions for incompetent patients should consult with colleagues, consult where existent the AD, the representative or relatives, the focus is clearly on the "collegial procedure" (L. 1111-4 CSP). That is, the decision-making procedure is limited to physicians and does not include the nursing staff, neither the representative nor the family

\footnotetext{
9 A House of Lords Select Committee on Medical Ethics was created in [26] with the aim to consider, amongst others, the ethical, legal and clinical aspects of withdrawing life-sustaining treatment for persons who cannot consent to treatments on their behalf.
} 
[4, pp. 182-183]. It appears then that the French model is what I will call here unilateral, that is, one-sided, rather than participative. It might be suggested that this approach points to both, the authority of physicians in the French system [25] and to a certain avoidance of discussing end-of-life issues with the patient which, despite changes following the broad influence of Anglo-American bioethics, is still often characteristic for countries with a traditional Catholic influence [51].

In England, too, there are concerns regarding the risk of abandoning the patient but the objection is that patients could be overwhelmed with too much information and too little communication [20]. What is at stake is whether the patient is really enabled to make autonomous decisions, and not whether the relationship with the physician could be destabilised. ${ }^{10}$ The fact that a doctor in England must respect the (incompetent) patient's prior written will does not imply that he must follow passively this direction. On the contrary, a doctor in England has to consider carefully whether a patient may have changed his or her mind, there have been advances in treatment since the directive was written or there is ambiguity in the wording of the directive [33, p. 171]. Both physician and patient-who has to make sure that others are aware of her/his preferences-are supposed to play an active role before the directive can be considered valid. Although some authors [30, 34] criticise the fact that advance refusals can be invalidated, it appears that the remaining tendency in English law is to emphasise patient participation and prioritise the individual's preferences-as least as long as they are clearly formulated.

The leading reason to introduce ADs in French law was not necessarily to enhance patient participation in the decision-making process but as Leonetti, the principle author of the law of 2005 and a physician himself stated, to "ease doctors' feelings of guilt" when discontinuing a treatment [4, p. 237]. Yet, the evaluation report of the law in 2008 revealed that the majority of French physicians are still unaware of the content of the new law and they do not approach discussions about anticipatory treatment decisions with their patients for fear of confronting patients with the possibility of their demise [4, p. 523]. It further appeared that ADs, occasionally equated with "dying wills" [4, p. 521], are strongly associated with death and the abandonment of the patient rather than considered as an important instrument for autonomous decision-making [3, p. 272].

Although patient autonomy occupies an important place in Western countries, not every country places this principle on the same level. The arguments employed in the French debate refer indeed to a high regard for the physician's ability and responsibility to guarantee the patient's best interests from a medical point of view. In this the French approach, in which the duty to safe life is placed above respect for autonomy, contrasts with the English model. The differences between these two countries mirror results of other studies comparing countries with an either patientor physician-centred approach $[9,25,45,47,51]$. What I shall argue next is that the rather hierarchical structure of the French doctor-patient relationship as well as the

\footnotetext{
10 This difference has been confirmed in interviews I undertook with French and English doctors. As yet, data analysis of the semi-structured 45 min lasting interviews with 14 English and 14 French physicians such as oncologists, nephrologists, neurologists is in its early stages and not ready to be published.
} 
preponderance of patient self-determination in England, echo the respective social and political system that is dominant in each of the countries.

\section{Autonomy and Welfare: Conflict Between the Individual's and Society's Interests}

In both countries, the principles respect for autonomy and welfare in terms of protection of life are important criteria. Yet, each country ranks these principles differently.

In England, respect of autonomy is a dominant principle and can be placed above the society's interests of welfare, as Lord Donaldson of Lymington M. R. endorsed in Bland:

This situation gives rise to a conflict between two interests, that of the patient and that of the society in which he lives. The patient's interest consists of his right to self-determination [...], even if it will damage his health or lead to his premature death. Society's interest is in upholding the concept that all human life is sacred and that it should be preserved if at all possible. It is well established that in the ultimate the right of the individual is paramount $[1$, p. 112].

This comment depicts the liberal socio-political and philosophical tradition in England where the individual's right of liberty is protected against public authorities since the Magna Carta in 1215. According to Locke [27], no authority should intervene in the private life of a person who is, as Mill 35] argues, free to do what they like as long as they do not restrain the liberty of others. Applied to the doctorpatient relationship the liberal model implies that a patient has the right, as Dickenson comments, to "pursue his or her own notion of well being" [11, p. 250]. This tradition is furthermore in line with the Protestant influence in England, emphasising the individual's ability to make their own decisions [15]. Crane's [10] study on variations in physicians' approaches to treatment of critically ill patients shows the correlation between religious background and the value accorded to sanctity of social life in terms of estimated capacity to fulfil social roles. Crane suggests that the physicians' attitudes towards end of life situations are influenced by their religious tradition in which they were socialised, rather than by the degree of religiosity of the singular person. According to her findings, physicians with a Protestant background attach less importance to the preservation of life and more to the individual's wishes and capacity to engage in social interactions. Finally, the individualistic English vision differs from the holistic concept that determines the relationship between individual and society/state in France.

In his comparative analysis, Münch illustrates the central difference between the English and French understanding of individual liberty [37, pp. 616-626]. The French constitution draws on the declaration of right of man and the citizen of 1789 , the first principle of which is the liberty of the individual. Yet, other than in England one's liberty is only guaranteed by assimilation within the community which is characterised by the equality of, and solidarity between, its members. In this 
perspective, which can be dated back to Rousseau's social contract, every individual's opinions and preferences are subject to the general will which represents the interests of the community as a whole [46]. According to the French republican concept, representatives of the community have the right to oppose an individual's will if the latter is not in accord with the general interests, such as the protection of life. As stipulated in a report of the French national ethics committee of 2000, regarding a sick person, the physician is such a representative of the community, and defends and promotes the values of the society [8, p. 11]. This statement suggests that the physician has thus the right to make decisions on behalf of the person if this is in accord with the community's common sense. It implies further that the patient has the "duty to follow the doctor's instructions, and to maximise his or her own health and well being" [11, p. 249]. Such an understanding of society matches with the Roman Catholic heritage which still informs secular France imbedding the individual in a rather hierarchical community where protection of life, even if the person is not longer able to fulfil social roles, and the physician's authority of decision-making have a strong value [10, pp. 173-179]. This observation reminds findings of studies regarding ADs in other Catholicinfluenced countries [31].

In such a context, the international Anglophone bioethical debate on patient autonomy, which emerged in the 1970s, had little influence on French medical ethics. The weight given to (previously) expressed patients' wishes as expressed in the new law is due to only recent developments. Although patients' preferences gain gradually more value, there is a degree of ambivalence about this development. This ambivalence arises from the suspicion that pro-autonomy developments signal a loss of solidarity as well as threats to a physician's legitimacy to make decisions on their patient's behalf. Taking into account the attitudes of French doctors I observed in a previous study regarding end-of-life practices in France and in Germany [25] the question arises as to whether the responsibility argument points to the defence of the primacy of the medical viewpoint rather than to the in ethical debate so often cited principle of the sanctity of life (e.g. [16]).

\section{Conclusion}

The fact that ADs have binding force in English law rests on a socio-political and philosophical tradition that accords a strong value to autonomy, rather than to solidarity. On the contrary, the weak status of ADs in French law and the importance accorded to the physician's responsibility to protect the patient's physical well-being testifies to the prioritising of the latter over the individual's preferences and wishes [45]. In the same way, the conflict between two values generates different ethical preoccupations in each country. Whereas the arguments in England concern the respect for and the authenticity of the autonomous will, the French debate focuses on the risk that the physician could lose her sense of responsibility and solidarity with the vulnerable person if advance directives were legally binding. Finally, the ethical concerns that exist in each country regarding 
advance directives raise doubts about whether these devices are not only an attractive theoretical idea which is hardly applicable in practice.

A fuller exploration of this hypothesis would require further research. Indeed, in order to develop and verify this hypothesis, more empirical research is also needed ${ }^{11}$ so as to clarify the advantages and disadvantages of each model in daily clinical practice, as well as improve policy-making in England and France, and in a broader context, in Europe and beyond [6, p. 203]. For now, I hope to have shown that concepts expressed in different laws emphasise different accounts of values, which are informed by different socio-political structures.

Acknowledgments This paper forms part of wider research comparing policies, implementations and attitudes towards advance directives in England and France funded by an EU grant for the FP7 project, "Advance decision-making: Advance directives and proxy decision-making in France and in England" (ADVANCED - FP7-PEOPLE-2009-IEF-254825). An earlier version of the paper was presented at a workshop supported by the Institute for Advanced Studies and organised by the Centre for Ethics in Medicine, University of Bristol, "LEAP_Advance decision-making at the end-of-life", in September 2011. I am grateful to the participants who contributed to discussion of the paper and to Kerry Gutridge for reviewing the text. I would particularly like to thank Richard Huxtable for his support and detailed comments on earlier drafts. Finally, I would like to thank the anonymous referees for critical comments and suggestions that led to improvements in the quality of this paper.

\section{References}

1. Airedale NHS Trust v Bland [1993] AC 789.

2. Assemblée Nationale. (2004). Mission d'information sur l'accompagnement de la fin de vie, $\mathrm{n}^{\circ} 1708$, vol. 1.

3. Assemblée Nationale. (2004). Mission d'information sur l'accompagnement de la fin de vie, $\mathrm{n}^{\circ} 1708$, vol. 2.

4. Assemblée Nationale. (2008). Mission d'évaluation de la loi $n^{\circ}$ 2005-370 du 22 avril 2005 relative aux droits des malades et à la fin de vie, $\mathrm{n}^{\circ} 1287$, vol. 2.

5. Beauchamp, T. L., \& Childress, J. F. (2008). Principles of biomedical ethics (6th ed.). New York: Oxford University Press.

6. Blank, R. H. (2011). End-of-life decision making across cultures. The Journal of Law, Medicine and Ethics, 39, 201-214.

7. BMA. (1995). Advanced statements about medical treatment. London: BMJ Publishing Group.

8. CCNE. (2000). Avis $n^{\circ} 63$ Fin de vie, arrêt de vie, euthanasie. Éthique et recherche biomédicale.

9. Cohen, J., Marcoux, I., Bilsen, J., Deboosere, P., Van der Wal, G., \& Deliens, L. (2006). European public acceptance of euthanasia: Socio-demographic and cultural factors associated with the acceptance of euthanasia in 33 European countries. Social Sciences and Medicine, 63, 743-756.

10. Crane, D. (2009). The sanctity of social life: Physicians' treatment of critically Ill patients. New Brunswick: Transaction Publishers (Original work published 1977).

11. Dickenson, D. (1999). Cross-cultural issues in European bioethics. Bioethics, 913, 249-255.

12. Ditto, P. H., et al. (2006). Context changes choices: A prospective study of the effects of hospitalization on life-sustaining treatment preferences. Medical Decision Making, 26, 313-322.

13. Dresser, R. (1986). Life, death, and incompetent patients: Conceptual infirmities and hidden values in the law. Arizona Law Review, 28, 373-405.

14. Dunn, M., \& Foster, C. (2010). Autonomy and welfare as amici curiae. Medical Law Review, 18, 86-95.

15. Durkheim, E. (2007). Le suicide. Paris: PUF (Original work published 1897).

16. Dworkin, R. (1993). Life's dominion: An argument about abortion, Euthanasia, and individual freedom. New York: Alfred A. Knopf.

\footnotetext{
${ }^{11}$ Further papers discussing the empirical outcomes of my ongoing research will follow.
} 
17. Fagerlin, A., \& Schneider, C. E. (2004). Enough: The failure of the living will. Hastings Center Report, 34, 30-42.

18. Feuillet, B. (2011). Les directives anticipées en France, un indice de consentement à effets limités. In S. Negri (Ed.), Self-determination, dignity and end-of-life care. Regulating advance directives in international and comparative perspective (pp. 195-207). Leiden, Boston: Martinus Nijhoff Publishers.

19. Foster, C. (2009). Choosing life, choosing death. The tyranny of autonomy in medical ethics and law. Oxford: Hart Publishing.

20. Fovargue, S., \& Miola, J. (2010). One step forward, two steps back? The GMC, the common law and 'informed' consent'. Journal of Medical Ethics, 36, 494-497.

21. GMC. (2008). Consent: Patients and doctors making decisions together. London: General Medical Council.

22. GMC. (2010). Treatment and care towards the end of life: Good practices in decision making. London: General Medical Council.

23. HE v A Hospital NHS Trust [2003] 2 FLR 408 (FD).

24. Hope, T., Slowther, A., \& Eccles, J. (2009). Best interests, dementia and the Mental Capacity Act (2005). Journal of Medical Ethics, 35, 733-738.

25. Horn, R. (2011, forthcoming). Euthanasia and end-of-life practices in France and Germany. A comparative study. Medicine, Health Care and Philosophy. doi:10.1007/s11019-011-9357-5.

26. House of Lords. (1994). Report of the select committee on medical ethics. London: HMSO.

27. Locke, J (1993) The two treatises of government. Ed. by Goldie M. London: Everyman (Original work published 1690).

28. Loi n . (2002-303). du 4 mars 2002 relative aux droits des malades et à la qualité du système de santé. Journal Officiel 54, 4118.

29. Loi n ${ }^{\circ}$. (2005-370). du 22 avril 2005 relative aux droits des malades et à la fin de vie. Journal Officiel $59,7089$.

30. Maclean, A. R. (2008). Advance directives and the rocky waters of anticipatory decision-making. Medical Law Review, 16, 1-22.

31. Meñaca, A., Evans, N., Andrew, E., Toscani, F., Finetti, S., Gómez-Batiste, X. et al. (2011). End-of-life care across Southern Europe: A critical review of cultural similarities and differences between Italy, Spain and Portugal. Critical Review in Oncology Hematology. doi:10.1016/j.critrevonc.2011.06.002.

32. Mendelson, D., \& Stoltzfus Jost, T. (2003). A comparative study of the law of palliative care and endof-life treatment. Journal of Law, Medicine and Ethics, 31, 134-135.

33. Mental Capacity Act Code of Practice. (2007). Chapter 4 available at http://www.opsi.gov.uk/acts/ acts2005/related/ukpgacop_20050009_en.pdf. Accessed 6 September 2011.

34. Michalowski, S. (2005). Advance refusals of life-sustaining medical treatment: The relativity of an absolute right. The Modern Law Review, 68, 958-982.

35. Mill, M. S. (2005). On liberty. New York: Cosimo classics (Original work published 1859).

36. Mr Leslie Burke v GMC [2005] EWCA Civ 1003.

37. Münch, R. (1986). Die Kultur der Moderne (2) Ihre Entwicklung in Frankreich und Deutschland. Frankfurt/Main: Suhrkamp.

38. Onwuteaka-Philipsen, B. D., Fisher, S., Cartwright, C., Deliens, L., Miccinesi, G., Norup, M., et al. (2006). End-of-life decision making in Europe and Australia. Archives for Internal Medicine, 166, 921-929.

39. Parfit, D. (1984). Reasons and persons. Oxford: Clarendon Press.

40. Re AK (medical treatment: consent) [2001] 1 FLR 129.

41. Re B (adult: refusal of medical treatment) [2002] 2 All ER 449.

42. Re C (adult: refusal of treatment) [1994] 1 WLR 290.

43. Re T (adult: refusal of treatment) [1992] 4 All ER 649.

44. Ricot, J. (2008). Directives anticipées, révélateur de la nouvelle relation de soin. Bulletin de la Société des Sciences Médicales, 3, 399-413.

45. Rodríguez-Arias, D., et al. (2007). Advance directives and the family: French and American perspectives. Clinical Ethics, 2, 139-145.

46. Rousseau, J.-J. (2006) Du contrat social. Paris: Flammarion (Originial work publised 1762).

47. Schicktanz, S., Raz, A., \& Shalev, C. (2010). The cultural context of end-of-life ethics: A comparison of Germany and Israel. Cambridge Quaterly of Health Care Ethics, 19, 381-394.

48. Sidaway v Bethlem Royal Hospital Governors [1985] 1 All ER 643.

49. Sidaway v Board of Governors of the Bethlem Royal Hospital [1985] AC 871. 
50. Smith v Tunbridge Wells Health Authority [1994] 5 Med. LR 334.

51. Toscani, F., \& Farsides, C. (2006). Deception, catholicism, and hope: Understanding problems in the communication of unfavorable prognoses in traditionally-catholic countries. The American Journal of Bioethics, 6, W6-W18.

52. $W v M$ and $S$ and A NHS Primary Care Trust [2011] EWHC 2443. 